\title{
EVALUASI ADVERSE DRUG REACTION ANTIDIABETES BERDASARKAN ALGORITMA NARANJO DI BANGSAL RAWAT INAP RS PKU MUHAMMADIYAH YOGYAKARTA PERIODE DESEMBER 2011- JANUARI 2012
}

\section{EVALUATION OF ANTIDIABETIC ADVERSE DRUG REACTION USING THE NARANJO ALGORITHM FOR DIABETES MELLITUS PATIENS IN PKU MUHAMMADIYAH YOGYAKARTA HOSPITAL IN DECEMBER 2011-JANUARY 2012}

\author{
Fitriyani, Woro Supadmi \\ Fakultas Farmasi Universitas Ahmad Dahlan \\ Jl Prof Dr Soepomo Yogyakarta, Telp. (0274) 379418
}

\section{Abstrak}

Penggunaan obat antidiabetes dapat menimbulkan adverse drug reaction. Penelitian ini bertujuan untuk mengetahui evaluasi adverse drug reaction antidiabetes berdasarkan algoritma Naranjo di bangsal rawat inap RS PKU Muhammadiyah Yogyakarta periode Desember 2011-Januari 2012. Penelitian dilakukan dengan metode deskriptif. Data diambil dari kartu rekam medis dan hasil wawancara pasien diabetes melitus yang telah menggunakan obat antidiabetes setelah 3 hari. Data yang diperoleh dianalisis dengan menggunakan algoritma Naranjo. Hasil penelitian menunjukkan bahwa selama periode Desember 2011-Januari 2012 ada 17 pasien pria dan 14 pasien wanita dibangsal rawat inap RS PKU Muhammadiyah Jogyakarta. Obat antidiabetes yang digunakan pada pasien diabetes melitus adalah metformin, kombinasi metformin dengan glibenklamid, kombinasi metformin dengan insulin, kombinasi glimepirid dengan insulin dan insulin. Metode algoritma Naranjo tidak cocok digunakan untuk evaluasi adverse reaction obat antidiabetes di bangsal rawat inap RS PKU Muhammadiyah Yogyakarta, karena dari 10 pertanyaan yang ada pada algoritma Naranjo hanya 4 pertanyaan yang bisa terjawab. Hal Ini disebabkan karena tidak terdapat data untuk menjawab pertanyaan. Penelitian tentang efek samping sebaiknya dilakukan dengan metode cohort dengan wawancara dan monitoring pasien.

Kata kunci : Diabetes Melitus, Efek Samping, Skala Algoritma Naranjo 


\section{Abstract}

This study is aimed to evaluated the antidiabetic adverse reaction using the Naranjo algorithm for diabetes mellitus patients in PKU Muhammadiyah Hospital Yogyakarta for period December 2011-January 2012. This study used descriptive method. The data was collected from the medical record and interviews from patients with diabetes mellitus who had used antidiabetic drugs after 3 days. The data were analyzed using the Naranjo algorithm. The results showed that during the period December 2011-January 2012 there were 17 male patients and 14 female patients with diabetes mellitus. The antidiabetic drugs that used to patients were metformin, metformin combined with glibenclamide, metformin combined with insulin, the combination with insulin and insulin glimepirid. Then, the study showed that Naranjo algorithm method was not suitable for evaluation the antidiabetic adverse reaction for diabetes mellitus patients in PKU Muhammadiyah Hospital in Yogyakarta for period December 2011-January 2012, because from 10 questions on the Naranjo algorithm there were only 4 questions that could be answered. It's because there was not data to answer questions. Research on the side effects cohort method should be done with the interview and patient monitoring.

Key word : Diabetes Mellitus, Adverse drug reaction, Naranjo algorithm

\section{PENDAHULUAN}

Diabetes Melitus (DM) adalah gangguan metabolisme yang secara genetis dan klinis termasuk heterogen dengan manifestasi berupa hilangnya toleransi karbohidrat. Jika telah berkembang penuh secara klinis, maka DM ditandai dengan hiperglikemia puasa dan postpandial, aterosklerotik dan penyakit vaskular mikroangiopati, dan neuropati (Scteingar, 1992).

Intervensi farmakologis (penggunaan obat) DM dapat menyebabkan terjadinya ADR. Adverse drug reaction (ADR) dapat memperburuk keadaan pasien, untuk itu harus dilakukan pemantauan atau monitoring Adverse drug reactionobat. Algoritma Naranjo adalah kuisoner yang dirancang oleh Naranjo untuk menentukan apakah efek yang merugikan disebabkan oleh obat atau faktor lain. Dalam algoritma Naranjo ada 10 pertanyaan yang diguna- kan untuk menilai apakah efek merugi- kan tersebut disebabkan penggunaan obat, digunakan untuk menyimpulkan kejadian efek samping, jika skor total 9 atau lebih disimpulkan bahwa kejadian ADR tinggi (definite), skor total 5-8 Kemungkinan terjadi ADR (probable), skor total 1-4 mungkin merupakan ADR (possible), kecil atau sama dengan nol (doubtful) maka ADR diragukan (Doherty, 2009).

Penelitian ini bertujuan untuk mengetahui evaluasi adverse drug reaction antidiabetes berdasarkan algoritma naranjo di bangsal rawat inap RS PKU Muhammadiyah Yogyakarta. 


\section{METODE PENELITIAN}

\section{Rancangan Penelitian}

Penelitian ini termasuk jenis penelitian bersifat deskriptif. Pengumpulan data dilakukan dengan cara wawancara langsung dengan pasien dan dilengkapi dengan mengamati data dari kartu rekam medis pasien.

\section{Definisi Operasional}

Pasien diabetes melitus merupakan pasien yang terdiagnosa diabetes melitus dengan penyakit penyerta atau tanpa penyakit penyerta di bangsal rawat inap RS PKU Muhammadiyah Yogyakarta periode Desember 2011-Januari 2012. Adverse drug reaction adalah setiap kejadian yang tidak dikehendaki yang terjadi pada pasien setelah 3 hari menggunakan obat antidiabetes di bangsal rawat inap RS PKU Muhammadiyah Yogyakarta periode Desember 2011-Januari 2012. Obat antidiabetes adalah semua obat anti- diabetes yang diberikan secara parenteral dan oral pada pasien diabetes melitus. Penyakit penyerta pada pasien diabetes meliputi semua penyakit yang didiagnosa oleh dokter selain diabetes melitus, seperti anemia, infeksi saluran kemih, hepatitis dan lain-lain. Algoritma Naranjo merupakan kuesioner yang digunakan untuk mengidentifikasi munculnya efek samping. Kuisioner dan skor dari jawaban Algoritme Naranjo seperti pada Tabel I.

\section{Populasi Target dan Populasi Terjangkau}

Populasi merupakan suatu kumpulan menyeluruh dari suatu obyek yang merupakan perhatian peneliti, dalam penelitian ini populasinya adalah seluruh pasien diabetes tipe 2 di bangsal rawat inap RS PKU Muhammadiyah Yogyakarta. Populasi target adalah pasien diabetes melitus tahun 2011 dan 2012 yang dirawat di bangsal rawat inap RS PKU Muhammadiyah Yogyakarta. Populasi terjangkau adalah populasi

Tabel I . Kuisioner dan skor dari jawaban Algoritme Naranjo

\begin{tabular}{|c|l|c|c|c|}
\hline No & \multicolumn{1}{|c|}{ Reaksi Obat yg Merugikan (ROM) } & Ya & Tidak & $\begin{array}{c}\text { Tidak } \\
\text { Tahu }\end{array}$ \\
\hline 01 & \multicolumn{1}{|c|}{ Apakah ada laporan yang jelas tentang ROM tsb pada waktu lampau? } & +1 & 0 & 0 \\
\hline 02 & Apakah ROM terjadi stelah pemberian obat yang dicurigai sbg penyebab ter-jadinya ROM ? & +2 & -1 & 0 \\
\hline 03 & Apakah ROM berkurang ketika obat dihentikan atau ketika diberi obat antagonis & +1 & 0 & 0 \\
\hline 04 & Apakah ROM timbul lagi ketika obat tsb diberikan lagi ? & +2 & -1 & 0 \\
\hline 05 & Adakah alternatif lain penyebab ROM pada pasien tersebut? & -1 & +2 & 0 \\
\hline 06 & Apakah ROM juga timbul ketika diberikan plasebo ? & -1 & +1 & 0 \\
\hline 07 & Apakah Obat berada pada konsentrasi toksis dalam darah ? & +1 & 0 & 0 \\
\hline 08 & Apakah ROM meningkat ketika dosis ditingkatkan atau berkurang ketika dosis diturunkan? & +1 & 0 & 0 \\
\hline 09 & $\begin{array}{l}\text { Apakah pasien pernah mengalami ROM yang sama di waktu lampau ketika obat yang sama atau } \\
\text { turunannya diberikan? }\end{array}$ & +1 & 0 & 0 \\
\hline 10 & Apakah diagnosis ROM tersebut didukung oleh bukti yang obyektif? & +1 & 0 & 0 \\
\hline
\end{tabular}


target pada periode Desember 2011Januari 2012.

\section{Pengumpulan Data}

Jenis data pada penelitian ini yaitu data primer dan data sekunder. Data primer berupa wawancara (interview) kepada pasien tentang keluhan pasien setelah menggunakan obat antidiabetes. Data sekunder berupa data pengobatan pasien dari kartu rekam medis dan hasil pengukuran laboratoriun klinis. Data sekunder penelitian ini adalah sebagai berikut: Jenis kelamin dan usia, Anamnesis penyakit, Diagnosa penyakit, Hasil pemeriksaan laboratorium pasien selama dirawat di Rumah sakit, Pengobatan yang diberikan pada pasien selama dirawat di rumah sakit, Kadar gula darah pasien.

\section{Analisis Data}

Data disajikan dalam bentuk tabel meliputi distribusi pasien berdasarkan jenis kelamin dan usia, distribusi pasien berdasarkan diagnosa dan lama rawat inap, pola penggunaan obat antidiabetes, gambaran ADR antidiabetes. Data-data tersebut dibutuhkan untuk menganalisis kejadian ADR antidiabetes.

\section{HASIL DAN PEMBAHASAN}

\section{Distribusi pasien DM berdasarkan jenis kelamin dan usia}

Para ahli berpendapat bahwa dengan meningkatnya umur, intoleransi terhadap glukosa juga meningkat. Peningkatan kadar glukosa darah pada usia lanjut disebabkan oleh fungsi sel pankreas dan sekresi insulin yang menurun. Perubahan tersebut berkaitan dengan resistensi insulin akibat kurangnya massa otot dan aktifitas fisik yang berkurang. Distribusi pasien DM berdasarkan usia dan jenis kelamin pada Tabel II.

Tabel II. Distribusi pasien DM berdasarkan jenis kelamin dan usia di bangsal rawat inap $R S$

PKU Muhammadiyah Yogyakarta periode

Desember 2011-Januari 2012

\begin{tabular}{ccccc}
\hline & \multirow{2}{*}{$\begin{array}{c}\text { Kelompok } \\
\text { No. }\end{array}$} & $\begin{array}{c}\text { Umur } \\
\text { (tahun) }\end{array}$ & \multicolumn{2}{c}{ Penis Kelamin } \\
\cline { 3 - 4 } & $20-29$ & - & Wanita \\
\hline 1 & $30-39$ & - & - \\
2 & $40-49$ & 4 & - \\
3 & $50-59$ & 6 & - \\
\hline 4 & 260 & 6 & 7 \\
\hline 5 & & $\mathbf{1 7}$ & $\mathbf{1 4}$ \\
\hline
\end{tabular}

Berdasarkan Tabel II dapat dilihat bahwa semakin bertambahnya usia maka semakin tinggi jumlah penderita diabetes. Berdasarkan hasil penelitian jenis kelamin pria dan wanita angka kejadian hampir sama. Pasien pria lebih banyak menderita DM dibanding pasien wanita. Penelitian yang dilakukan oleh Phan, dkk (2004) diperoleh bahwa dibandingkan dengan perempuan, jumlah pria lebih banyak yang menderita DM. Penelitian yang dilakukan oleh Wild, dkk di Amerika Serikat (2004) dengan sampel pasien DM usia 60-74 tahun diperoleh 20,2 \% penderita diabetes adalah pria, sedangkan wanita hanya $17,8 \%$.

\section{Pasien DM berdasarkan diagnosa dan lama rawat inap}

Berdasarkan Tabel III dapat dilihat bahwa kelompok pasien yang paling banyak yaitu pasien dengan lama rawat inap 3-7 hari. Pasien yang paling 
Tabel III. Diagnosa penyakit dan lama rawat inap pasien di bangsal rawat inap RS PKU Muhammadiyah Yogyakarta periode Desember 2011-Januari 2012

\begin{tabular}{|c|c|c|c|}
\hline \multirow[b]{2}{*}{ Diagnosa } & \multicolumn{3}{|c|}{ Jumlah Pasien } \\
\hline & $\begin{array}{c}\text { Lama Rawat Inap } \\
\text { 3-7 Hari }\end{array}$ & $\begin{array}{c}\text { Lama Rawat Inap } \\
\text { 8-12 Hari }\end{array}$ & $\begin{array}{c}\text { Lama Rawat Inap } \\
13-17 \text { Hari }\end{array}$ \\
\hline Diabetes & 7 & & - \\
\hline Diabetes + hipertensi & 3 & 2 & - \\
\hline Diabetes + stroke + hipertensi & - & 1 & - \\
\hline Diabetes + hipertensi + anemia & 1 & - & - \\
\hline Diabetes + hipertensi + gangguan pencernaan & 1 & 1 & - \\
\hline Diabetes + hipertensi + gangguan pernafasan dan pencernaan & 1 & - & - \\
\hline Diabetes + infeksi & 3 & 1 & - \\
\hline Diabetes + pencernaan & 1 & & - \\
\hline Dibetes + vertigo & 1 & 1 & - \\
\hline Diabetes + gagal jantung & 1 & - & - \\
\hline Diabetes + stroke + hipertensi & - & - & 1 \\
\hline Diabetes + gangguan pernafasan & 3 & 2 & - \\
\hline Jumlah & 22 & 8 & 1 \\
\hline
\end{tabular}

lama dirawat inap yaitu pasien DM dengan stroke dan hipertensi. Lama rawat inap dipengaruhi juga oleh penyakit penyerta, semakin kompleks penyakit penyerta kemungkinan semakin lama pula pasien dirawat inap dan juga semakin banyak jenis obat yang digunakan, sehingga kemungkinan terjadinya ADR semakin tinggi. Akan tetapi pada penelitian ini tidak dapat memberikan informasi tentang hubungan antara lama rawat, banyak jenis obat yang digunakan dan kejadian efek samping. Hal ini disebabkan peneliti hanya mengamati kejadian ADR setelah tiga hari penggunaan obat untuk semua sampel penelitian.

\section{Pola Penggunaan Obat Antidiabetes}

Obat antidiabetes yang banyak digunakan dalam penelitian ini, adalah insulin yakni sebanyak 26 pasien dari 31 pasien. Jenis insulin yang digunakan yaitu jenis insulin aspart dan insulin glusine yang merupakan jenis insulin yang bekerja cepat. Insulin campuran (mixtard) merupakan campuran dari $30 \%$ soluble insulin dan $70 \%$ isophane (NPH) insulin, diberikan kepada pasien yang sebelumnya telah rutin memakai jenis insulin tersebut.

\section{Evaluasi Adverse drug reaction}

Pertanyaan nomor 1 dijawab berdasarkan literatur Drug Related Problem (DIH) dan Side Effects of Drugs Annual 29. Pertanyaan nomor 2 ditanyakan langsung ke pasien. Pertanyaan nomor 3 dan 4 diberi skor 0 untuk semua obat karena intervensi ini tidak bisa dilakukan oleh peneliti. Pertanyaan nomor 5 di jawab dengan melihat ADR obat lain dan keluhan karena penyakit. Pertanyaan nomor 6 , nomor 7 dan nomor 8 diberi skor 0 untuk semua obat karena intervensi ini tidak bisa dilakukan oleh peneliti. Pertanyaan nomor 9 diberi skor 0 untuk semua obat 
Tabel IV. Pola Penggunaan Obat Antidiabetes Pada Pasien DM Di Bangsal Inap RS PKU Muhammadiyah Yogyakarta Periode Desember 2011-Januari 2012

\begin{tabular}{|c|c|c|c|}
\hline No. & Golongan Obat & Jenis obat & Jumlah \\
\hline 1 & Biguanid & Metformin & 3 \\
\hline 2 & Sulfonilurea + Biguanid & Metformin + glibenklamid & 2 \\
\hline \multirow[t]{2}{*}{3} & Biguanid + insulin & Metformin + insulin glusine & 1 \\
\hline & & Metformin + insulin aspart & 1 \\
\hline 4 & Sulfonilurea + insulin & Glimepirid + insulin glusine & 1 \\
\hline \multirow[t]{4}{*}{5} & Insulin & Aspart & 16 \\
\hline & & Glusine & 6 \\
\hline & & Campuran $30 \%$ soluble insulin dan $70 \%$ isophane (NPH) & 1 \\
\hline & & Total & 31 \\
\hline
\end{tabular}

karena informasi yang diperoleh tidak akurat (bias). Pertanyaan nomor 10 dari algoritma Naranjo (Apakah ADR yang terjadi mempunyai petunjuk yang kuat). Petunjuk yang kuat dalam penelitian ini berupa data laboratorium.

Pada Tabel V dapat dilihat dari tiga pasien yang menggunakan metformin dua dari tiga pasien tersebut mengalami mual. Berdasarkan analisis dengan menggunakan algoritma Naranjo diperoleh skor total 1-4 "possible" yang artinya mual yang dialami pasien mungkin merupakan Adverse drug reactiondari metformin. Menurut Lacy dkk pasien diabetes melitus yang menggunakan metformin 7-10\% pasien mengalami mual (Lacy, dkk, 2010)

Pada penelitian ini hanya ada dua pasien yang mengunakan kombinasi metformin dan glibenklamid, salah satu pasien tersebut mengalami susah buang air besar. Analisis dengan algoritma Naranjo diperoleh skor total 1-4 "possible" yang artinya susah buang air besar yang dialami pasien tersebuat mungkin merupakan ADR dari penggunaan metformin dan glibenklamid. Menurut Lacy dkk pasien yang meng- gunakan glibenklamid dapat mengalami konstipasi walau jarang ada laporan mengenai ADR tersebut (Lacy, dkk, 2010) .

Pasien yang menggunakan kombinasi metformin dan insulin glusine pada penelitian ini mengalami badan terasa lemas. Analisis dengan algoritma Naranjo diperoleh skor total 1-4 "possible" yang artinya badan lemas yang dialami pasien mungkin merupakan ADR dari penggunaan metformin dan insulin glusine. Insulin dapat menyebabkan kelemahan otot (muscle wekness) Lacy, dkk, 2010).

Kombinasi metformin dan insulin glusine diberikan pada satu pasien. Setelah menggunakan kombinasi obat tersebut pasien mengalami badan terasa lemas, muka pucat dan hipoglikemia. Analisis dengan algoritma Naranjo diperoleh skor total 1-4 "possible" yang artinya badan terasa lemas dan muka pucat mungkin merupakan ADR dari penggunaan metformin dan insulin glusine. Hipoglikemia yang dialami pasien setelah menggunakan kombinasi metformin dan insulin glusine setelah dianalisis dengan algoritma Naranjo, 
Tabel V. Gambaran adverse drug reaction antidiabetes pada pasien DM di bangsal rawat inap RS PKU Muhammadiyah Yogyakarta

\begin{tabular}{|c|c|c|c|}
\hline Nama Obat & No Pasien & Keluhan Pasien & Skor Algoritma Naranjo \\
\hline \multirow[t]{3}{*}{ Metformin } & 4 & Mual & 2 \\
\hline & 19 & - & - \\
\hline & 22 & Mual & 2 \\
\hline \multirow[t]{2}{*}{ Metformin + glibenklamid } & 16 & Susah buang air besar & 2 \\
\hline & 31 & - & - \\
\hline Metformin + insulin glusine & 9 & Lemas & 2 \\
\hline \multirow[t]{3}{*}{ Metformin + insulin aspart } & 12 & Badan lemas & 3 \\
\hline & & Pucat & 3 \\
\hline & & Hipoglikemia & 6 \\
\hline \multirow[t]{21}{*}{ Insulin aspart } & 2 & - & - \\
\hline & 3 & - & - \\
\hline & 5 & Pusing & 2 \\
\hline & 8 & Mual & 2 \\
\hline & & Pusing & 2 \\
\hline & 10 & - & - \\
\hline & 11 & Badan lemas & 3 \\
\hline & & Nafsu makan turun & 1 \\
\hline & 13 & Badan lemas & 3 \\
\hline & & Pucat & 3 \\
\hline & 15 & Badan lemas & 3 \\
\hline & 18 & - & - \\
\hline & 23 & Mual & - \\
\hline & 24 & Lemas & 2 \\
\hline & & Pusing & 2 \\
\hline & 26 & Lemas & 2 \\
\hline & & Pucat & 2 \\
\hline & & Hipoglikemia & 6 \\
\hline & 27 & Lemas & 2 \\
\hline & 28 & Mual & 2 \\
\hline & & Muntah & 2 \\
\hline \multirow[t]{11}{*}{ Insulin Glusine } & 6 & Pusing & 2 \\
\hline & & Lemas & 2 \\
\hline & 7 & - & - \\
\hline & 14 & Mual & 2 \\
\hline & & Muntah & 2 \\
\hline & 20 & Mual & 3 \\
\hline & 25 & Lemas & 2 \\
\hline & & Hipoglikemia & 6 \\
\hline & 30 & Pusing & 2 \\
\hline & & Mual & 2 \\
\hline & & Hipoglikemia & 6 \\
\hline \multirow{2}{*}{$\begin{array}{l}\text { Campuran } 30 \% \text { soluble insulin dan } \\
70 \% \text { isophane }\end{array}$} & 1 & Lemas & 2 \\
\hline & & Hipoglikemia & 6 \\
\hline
\end{tabular}


diperoleh skor total 5-8 "probable" yang artinya kemungkinan terjadi hipoglikemia karena penggunaan metformin dan insulin glusine.

\section{Kelemahan Penelitian}

Penelitian adverse drug reaction antidiabetes dengan menggunakan algoritma Naranjo mempunyai kelemahan diantaranya:

1. Tidak semua pertanyaan algoritma Naranjo dapat terjawab. 10 pertanyaan algoritma Naranjo hanya 4 pertanyaan yang bisa terjawab. Hal ini dikarenakan keterbatasan data yang ada, waktu penelitian yang singkat dan intervensi yang tidak dapat dilakukan.

2. Data yang dibutuhkan untuk menjawab pertanyaan tidak lengkap karena data pasien tidak lengkap.

3. Keluhan yang pasien rasakan belum dapat dipastikan karena adverse drug reaction karena data pendukung untuk memastikan bukan karena penyakit penyerta tidak diperoleh.

\section{KESIMPULAN DAN SARAN}

\section{Kesimpulan}

Berdasarkan hasil penelitian pasien DM dibangsal rawat inap RS PKU Muhammadiyah Yogyakarta periode Desember 2011-Januari 2012 yaitu 17 pasien pria dan wanita 14 pasien. Pola penggunaan obat antidiabetes pada pasien diabetes di bangsal rawat inap RS PKU Muhammadiyah Yogyakarta yaitu metformin, kombinasi metformin dan glibenklamid, kombinasi metformin dengan insulin glusine, kombinasi metformin dengan insulin aspart, kombinasi glimepirid dengan insulin, insulin glusine, insulin aspart dan insulin campuran $(70 \%$ isophane $(\mathrm{NPH})$ dan $30 \%$ soluble insulin). Penelitian adverse drug reaction dengan metode algoritma Naranjo tidak cocok digunakan di Indonesia, dari 10 pertanyaan hanya 4 pertanyaan yang bisa terjawab.

\section{Saran}

Penelitian tentang adverse drug reaction di Indonesia sebaiknya menggunakan metode selain algoritma Naranjo misalnya monitoring efek samping obat dengan metode cohort.

\section{DAFTAR PUSTAKA}

Doherty, M. J., Algorithms for assessing the probability of an Adverse drug reaction. Journal Home page 2009.

Lacy,C.F. dkk, 2010, Drug Information Handbook. $18^{\text {th }}$ editionlexi-comp, USA.

Phan, H., Marcel C. S., Sarah C., Anthony L. Mark W. H., Millap W. H., Serotonin Syndrome Following a single $50 \mathrm{mg}$ dose of sertraline in a child. The Ohio State University,Elsevier 2008.

Schteingart, D.E., 1992, Metabolisme Glukosa dan Diabetes Melitus, dalam Price, S.A., and Wilson, L.M., Edisi VI, Patofisiologi Konsep Klinis Proses-Proses Penyakit, Hal 1259-1270, diterjemahkan oleh Brahm, U.P., EGC, Jakarta. 
Wild, S., Roglic, G., Green, A., Sicree for 2030. Dalam Diabetes Care R., dan King, H., Global 2004.

Prevalensi of Diabetes: Etimates for The Year 2000 and Projections 